\title{
Interventions in Nutrition Education for Improving the Performance of Integrated Health Care
}

\section{Intervensi Pendidikan Gizi Untuk Peningkatan Kinerja Posyandu}

\author{
Syamsul Alam ${ }^{* 1}$, Burhanuddin Bahar ${ }^{2}$ \\ ${ }^{1}$ Bagian Kesehatan Masyarakat, Universitas Islam Negeri Alauddin Makassar, Makassar \\ ${ }^{2}$ Bagian Kesehatan Masyarakat, Universitas Hasanuddin, Makassar
}

DOI: 10.24252/al-sihah.v13i1.21461

Received: 10 February 2021 / In Reviewed: 18 May 2021 / Accepted: 26 June 2021 / Available online: 30 June 2021 (O) The Authors 2021. This is an open access article under the CC BY-NC-SA 4.0 license

\begin{abstract}
The description of community behavior in utilizing existing health service facilities in their area can be seen from the success rate of the Posyandu program, namely the coverage of weighing children under five at the Posyandu. This study aims to examine that nutrition education interventions through community nutrition classes can increase the scope of integrated health care (posyandu) performance $(D / S, N / D)$ in Bulukumba Regency, Indonesia. This research design is quasi-experimental. The samples in this study were mothers of children under five who were in the intervention area $(n=107)$ and control $(n=113)$. The intervention group was given nutrition education through community nutrition class activities, while the control group was given counseling. The results showed that there were changes in the intervention group in the form of increased knowledge of mothers of children under five, increased parenting patterns of mothers of children under five, increased levels of community participation, and increased body weight of toddlers compared to the intervention group. control group. Community nutrition classes at posyandu can be used as a model in increasing the level of community participation in posyandu because there are changes in both knowledges, child care patterns, number of visits at posyandu $(D / S)$, and the number of toddlers who experience weight gain from the previous month's weighing (N/D) for increased significantly.
\end{abstract}

\begin{abstract}
ABSTRAK
Gambaran perilaku masyarakat dalam memanfaatkan sarana pelayanan kesehatan yang ada didaerahnya dapat terlihat dari tingkat keberhasilan program Posyandu yaitu cakupan penimbangan balita di Posyandu. Penelitian ini bertujuan untuk menilai bahwa intervensi pendidikan gizi melalui kelas gizi masyarakat untuk meningkatkan cakupan kinerja posyandu (D/ S,N/D) di Kabupaten Bulukumba, Indonesia. Desain penelitian ini adalah quasi experiment. Sampel pada penelitian ini adalah ibu balita baik yang berada pada wilayah intervensi $(n=107)$ dan kontrol $(n=113)$. Pada kelompok intervensi diberikan pendidikan gizi melalui kegiatan kelas gizi masyarakat sedangkan pada kelompok kontrol diberikan penyuluhan. Hasil penelitian menunjukkan bahwa terdapat perubahan pada kelompok intervensi berupa peningkatan pengetahuan ibu balita, peningkatan pola asuh ibu balita, peningkatan tingkat partisipasi masyarakat, serta peningkatan berat badan balita dibandingkan pada kelompok kontrol. Kelas gizi masyarakat di posyandu dapat dijadikan sebagai salah satu model dalam memperbaiki tingkat partisipasi masyarakat di posyandu karena terjadi perubahan baik pengetahuan, pola asuh ibu pada anak, jumlah kunjungan di posyandu (D/S) dan jumlah balita yang naik berat badannya dari penimbangan bulan sebelumnya (N/D) agar meningkat secara signifikan
\end{abstract}

\section{GRAPHICAL ABSTRACT}



Keyword

counseling; knowledge; nutrition class; parenting; performance of integrated health care

Kata Kunci:

kelas gizi; kinerja posyandu; pengetahuan; penyuluhan; pola asuh

\section{* Correspondence}

BTN Ranggong Permai a14 No.4 Tamangapa

Raya, Makassar

Email: syamsul.alam@uin-alauddin.ac.id 


\section{PENDAHULUAN}

Indikator keberhasilan program kesehatan masyarakat di Indonesia dapat dinilai berdasarkan derajat kesehatan masyarakat. Derajat kesehatan masyarakat dapat ditentukan dengan menilai Indeks Pembangunan Kesehatan Masyarakat (IPKM) dan Indeks Keluarga Sehat (IKS) (Indrawati \& Tjandrarini, 2018). Salah satu indikator dalam penilaian IPKM dan IKS adalah pemantauan pertumbuhan dan status gizi balita (Budiono, 2013; Tjandra et al., 2018). Pemantauan pertumbuhan dan penilaian status gizi balita dapat diperoleh dengan memanfaatkan sarana pelayanan kesehatan secara optimal yang tersedia di masyarakat seperti posyandu (Di Cesare et al., 2015; Pratley, 2016). Menurut Menurut Chan et al. (2018) pelayanan kesehatan mempengaruhi status kesehatan masyarakat. Keberadaan dan pemanfaatan pelayanan kesehatan merupakan salah satu langkah strategis dalam mewujudkan peningkatan derajat kesehatan masyarakat yang kegiatannya menitikberatkan pada partisipasi dan kemandirian masyarakat menangani masalah kesehatan komunitas seperti memantau pertumbuhan dan status gizi balita secara rutin (Delaney, 2018)

Kegiatan pemantauan pertumbuhan dan penilaian status gizi yang dilaksanakan secara rutin melalui kegiatan posyandu memberikan dampak positif terhadap upaya perbaikan gizi dan peningkatan derajat kesehatan masyarakat (Kartika et al., 2018). Hal ini diperkuat adanya asumsi bahwa persepsi masyarakat terhadap program posyandu cukup positif, partisipasi masyarakat cukup tinggi. Posyandu memiliki peranan penting sebagai katalisator yang dapat mengubah pola pikir masyarakat terhadap kesehatan, salah satunya pemantauan tumbuh kembang anak (Islam et al., 2020; Criss et al., 2015). Beberapa penelitian menunjukkan bahwa anak balita yang mengunjungi posyandu untuk melakukan pemantauan berat badan, pemberian imunisasi, pemberian vitamin dan makanan tambahan merupakan alasan mendasar para orang tua/ pengasuh membawa anaknya aktif ke posyandu sehingga status gizi anak terpantau secara rutin (Destiadi et al., 2013; Adistie et al., 2018) Beberapa peneltian lain juga menunjukkan bahawa sebagian besar anak balita yang rutin ke posyandu akan memiliki status gizi baik dengan melibatkan partisipasi ibu (Abuya et al., 2012; Ranehov et al., 2019; Indriati \& Lidyawati, 2017).

Posyandu sebagai bentuk kegiatan peran serta masyarakat dengan tenaga pelaksana para kader sukarela maka partisipasi terutama tergantung dari kemauan dan kemampuan kader serta penerimaan masyarakat. Pemerintah hanya bersifat membantu dan membimbing namun kenyataanya manunjukkan bahwa jumlah kunjugan ibu balita $(\mathrm{D} / \mathrm{S})$ masih rendah, dan pelaksanaan posyandu selama ini masih tertangani oleh petugas kesehatan dan bukan sepenuhnya oleh kader pada kegiatan 5 meja, keterampilan kader yang dirasa paling minimal adalah penyuluhan perorangan di meja IV nya tidak berfungsi. Data Riskesdas menunjukkan bahwa proporsi anak balita di Indonesia yang melakukan penimbangan rutin sebesar 44,6\% (2013) dan 54,6\% (2018), di Sulawesi selatan proporsi pemantauan pertumbuhan pada anak balita 
dalam satu terakhir yang ditimbang berat badannya sebesar $77,28 \%$ dan diukur tinggi/panjang badannya hanya 50,52\% (Kementerian Kesehatan RI, 2018). Sedangkan di Kab. Bulukumba yang ditimbang berat badannya sebesar $65,70 \%$ dan diukur tinggi/panjang badannya hanya 33,40\% (Yogiswara, B. A., \& Margawati, 2011). Data dari Dinas kesehatan Bulukumba tentang cakupan program gizi menunjukkan bahwa cakupan kegiatan posyandu $(\mathrm{D} / \mathrm{S})$ atau partisispasi masyarakat yang membawa anaknya ke posyandu $(65,5 \%$ dan $70,9 \%)$, ini menunjukkan masih di bawah standar pelayanan minimal yaitu $85 \%$. Sedangkan anak balita yang datang ke posyandu naik berat badannya berdasarkan garis pertumbuhan pada KMS (N/ D) $78,04 \%$ dan 79,9\% (Dinas Kesehatan Kabupaten Bulukumba, 2015).

Kegiatan posyandu memberikan andil besar terhadap meningkatnya derajat kesehatan masyarakat. Kualitas kesehatan yang semakin baik seperti makin membaiknya status gizi masyarakat, angka kematian ibu dan bayi yang menurun, terpantaunya pertumbuhan balita, bertambahnya pengetahuan masyarakat tentang kesehatan merupakan gambaran dari hasil pemanfaatan layanan kesehatan di posyandu (Hafifah \& Abidin, 2020). Namun, perubahan kualitas kesehatan yang terjadi belum memberikan dampak signifikan dengan tujuan posyandu (Saepuddin et al., 2017).

Partisipasi ibu balita datang menimbang di Posyandu yang rendah dan tidak rutin dapat menyebabkan terjadinya gangguan pertumbuhan balita karena berat badan dan tinggi/panjang badan tidak terpantau, selain itu balita yang tidak ke posyandu tidak memperoleh berbagai fasilitas layanan seperti konsultasi gizi dan kesehatan balita sehingga keadaan tersebut dapat berdampak pada pola pengasuhan anak. Beberapa penelitian menunjukkan adanya peningkatan frekuensi ibu balita ke posyandu setelah dilakukan pendampingan dan Learning Organization (LO) terhadap partisipasi posyandu (Aminuddin et al., 2011; Kosasih et al., 2018; Megawati \& Wiramihardja, 2019). Mengatasi permasalahan tersebut diupayakan adanya keterlibatan masyarakat secara aktif terhadap problem kesehatan yang terjadi di sekitarnya salah satunya melalui kelas gizi masyarakat berupa kegiatan pendampingan dan pelatihan. Berdasarkan data dan kajian di atas, maka diperlukan suatu penelitian tentang intervensi pendidikan gizi melalui model kelas gizi masyarakat terhadap peningkatan cakupan kinerja posyandu (D/S, N/D) di Kabupaten Bulukumba. Penelitian ini bertujuan menilai intervensi pendidikan gizi melalui kelas gizi masyarakat dapat meningkatkan cakupan kinerja posyandu (D/S,N/D) di Kabupaten Bulukumba.

\section{METODE PENELITIAN}

Rancangan penelitian adalah quasi experiment (eksprimen semu). Pengambilan sampel tidak dilakukan secara acak baik pada kelompok kontrol maupun kelompok eksperimen, dilakukan observasi awal untuk menilai dan menguji perubahan yang terjadi sebelum dan setelah intervensi. Lokasi Penelitian ini di Wilayah Kerja Puskesmas Salassae sebagai wilayah inter- 
Tabel 1

Perbedaan Kecukupan Asupan Energi Anak Balita Sebelum dan Seudah Kegiatan Kelas Gizi Masyarakat

\begin{tabular}{|c|c|c|c|c|c|c|c|c|}
\hline \multirow[t]{3}{*}{ Asupan Energi } & \multicolumn{8}{|c|}{ Kelompok } \\
\hline & \multicolumn{4}{|c|}{ Intervensi $(\mathrm{n}=107)$} & \multicolumn{4}{|c|}{ Kontrol $(n=113)$} \\
\hline & $\pm \mathrm{SD}$ & Min. & Maks & $p$ & $\pm \mathrm{SD}$ & Min. & Maks & $p$ \\
\hline Sebelum (Pre) & $87,72( \pm 12,76)$ & 48,41 & 106,85 & 0,000 & $96,74( \pm 14,24)$ & 63,29 & 130,71 & 0,000 \\
\hline Sesudah (Post) & $96,95( \pm 14,01)$ & 50,33 & 96,95 & & $99,93( \pm 14,50)$ & 140,37 & 140,37 & \\
\hline
\end{tabular}

vensi karena wilayah tersebut cakupan kinerja posyandunya masih di bawah standar pelayanan minimal kabupaten yaitu tingkat partisipasi masyarakat (D/S) 60,4\%. Sedangkan Wilayah Kerja Puskesmas Herlang merupakan wilayah cakupan dengan kinerja posyandu sesuai dengan SPM kabupaten yaitu $88,9 \%$. Sampel pada penelitian ini adalah ibu balita baik yang berada pada wilayah intervensi $(n=107)$ diperoleh dari wilayah dengan cakupan kinerja posyandu terendah (Desa Salassae) dan kontrol $(n=113)$ diperoleh berdasarkan cakupan kinerja posyandunya yang sudah sesuai atau di atas standar pelayanan minimal (Desa Pataro). Pada kelompok intervensi diberikan pendidikan gizi melalui kegiatan kelas gizi masyarakat sedangkan pada kelompok kontrol diberikan penyuluhan.

Data Primer berupa data cakupan kinerja posyandu (D/S, N/D) diperoleh dengan melakukan wawancara langsung kader posyandu dan obeservasi pada posyandu. Pengetahuan gizi dan pola asuh ibu balita diperoleh melalui wawancara langsung kepada responden, kuesioner yang digunakan diadopsi dari kusieoner Riset Kesehatan Dasar 2013. Untuk mendapatkan data ini dilakukan dua kali wawancara yaitu sebelum dan sesudah intervensi. Adapun data sekunder diperoleh dari data cakupan program gizi sebelum dan sesudah kegiatan diperoleh dari laporan FI dan FIII Gizi Puskesmas yang menjadi subyek penelitian. Data dianalisis sebelum dan setelah pelaksanaan kegiatan kelas gizi masyarakat dengan menggunakan uji wilcoxon signed rank untuk melihat perubahan pengetahuan dan pola asuh ibu balita serta cakupan kinerja di posyandu (D/S, N/D) sebelum dan setelah pelaksanaan kegiatan kelas gizi masyarakat dengan tingkat kemaknaan yang digunakan adalah $\alpha=0,05$.

\section{HASIL PENELITIAN}

Pada gambar 1 menunjukkan bahwa rata-rata nilai pengetahuan ibu balita tentang gizi terdapat peningkatan pada kelompok intervensi yaitu sebelum kelas gizi masyarakat $56,69 \%$ dan setelah kelas gizi masyarakat 73,52 sedangkan pada kelompok kontrol sebelum penyuluhan $70,38 \%$ dan setelah penyuluhan $73,74 \%$. Pengetahuan ibu balita tentang posyandu pada kelompok intervensi sebelum kelas gizi masyarakat 57,38\% dan setelah kelas gizi masyarakat 78,13 sedangkan pada kelompok kontrol sebelum penyuluhan $74,77 \%$ dan setelah penyuluhan 79,73\%. Rata - rata skor pengetahuan ibu balita yang merupakan komposit dari pengetahuan ibu tentang gizi anak balita dan pengetahuan 
Tabel 2

Perubahan Berat Badan Sebelum dan Seudah Kegiatan Kelas Gizi Masyarakat

\begin{tabular}{|c|c|c|c|c|c|c|c|c|}
\hline \multirow{3}{*}{$\begin{array}{c}\text { Perubahan Berat } \\
\text { Badan }\end{array}$} & \multicolumn{8}{|c|}{ Kelompok } \\
\hline & \multicolumn{4}{|c|}{ Intervensi $(\mathrm{n}=107)$} & \multicolumn{4}{|c|}{ Kontrol $(\mathrm{n}=113)$} \\
\hline & $\pm \mathrm{SD}$ & Maks & Min & $\bar{p}$ & $\pm \mathrm{SD}$ & Maks & Min & $p$ \\
\hline Sebelum (Pre) & $9,94( \pm 2,26)$ & 6,20 & 15,0 & 0,000 & $10,67( \pm 3,10)$ & 6,10 & 20,0 & 0,000 \\
\hline Sesudah (Post) & $10,15( \pm 2,17)$ & 6,80 & 15,0 & & $10,84( \pm 2,94)$ & 6,70 & 20,3 & \\
\hline
\end{tabular}

ibu tentang posyandu yaitu pengetahuan ibu pada kelompok intervensi sebelum kelas gizi masyarakat $57,19 \%$ dan setelah kelas gizi masyarakat 74,99 sedangkan pada kelompok kontrol sebelum penyuluhan $72,14 \%$ dan setelah penyuluhan 76,14\%. Hasil uji statistik Wilcoxon Signed Rank menunjukkan bahwa kelas gizi masyarakat dapat meningkatkan pengetahuan ibu balita (pengetahuan tentang gizi anak balita dan pengetahuan tentang posyandu) serta peningkatannya berbeda secara signifikan $(\mathrm{p}=0,000)$. Artinya Ada perbedaan yang signifikan terhadap peningkatan pengetahuan ibu balita sebelum dan sesudah pelaksanaan kelas gizi masyarakat.

Pada gambar 2 menunjukkan bahwa rata-rata skor pola asuh ibu balita tentang praktik Pemberian Makan Anak (PMA) terdapat peningkatan pada kelompok intervensi yaitu sebelum kelas gizi masyarakat $57,68 \%$ dan setelah kelas gizi masyarakat 72,11 sedangkan pada kelompok kontrol sebelum penyuluhan $75,66 \%$ dan setelah penyuluhan 79,59\%. Pola asuh tentang praktik Kesehatan dan Kebersihan Anak (PKA) pada kelompok intervensi sebelum kelas gizi masyarakat $60,58 \%$ dan setelah kelas gizi masyarakat 79,03 sedangkan pada kelompok kontrol sebelum penyuluhan $79,89 \%$ dan setelah penyuluhan $85,83 \%$.
Rata - rata skor pola asuh ibu balita yang merupakan komposit dari skor PMA dan PKA yaitu sebelum kelas gizi masyarakat $59,77 \%$ dan setelah kelas gizi masyarakat 79,03 sedangkan pada kelompok kontrol sebelum penyuluhan $76,84 \%$ dan setelah penyuluhan $81,34 \%$. Hasil uji statistik wilcoxon signed rank menunjukkan bahwa kelas gizi masyarakat dapat meningkatkan pola asuh ibu balita (PMA dan PKA) serta peningkatannya berbeda secara signifikan $(p=0,000)$. Artinya Ada perbedaan yang signifikan terhadap peningkatan pola asuh ibu balita sebelum dan sesudah pelaksanaan kelas gizi masyarakat.

Tabel 1 menunjukkan bahwa ratarata asupan energi anak balita sebelum pelaksanaan kelas gizi masyarakat pada kelompok intervensi yaitu $87,72 \%$ dan setelah kelas gizi masyarakat meningkat menjadi 96,95\%, sedangkan pada kelompok kontrol sebelum penyuluhan 96,74\% dan setelah penyuluhan 99,93\%. Hasil penelitian ini menunjukkan bahwa persentase asupan energi anak balita terjadi peningkatan sesudah pelaksanaan kelas gizi masyarakat pada kelompok intervensi dan penyuluhan pada kelompok kontrol. Hasil uji statistik wilcoxon signed rank menunjukkan bahwa kelas gizi masyarakat dapat meningkatkan asupan energi anak balita 


\section{Gambar 1}

Peningkatan Pengetahuan Ibu Balita Sebelum dan Seudah Mengikuti Kelas Gizi Masyarakat

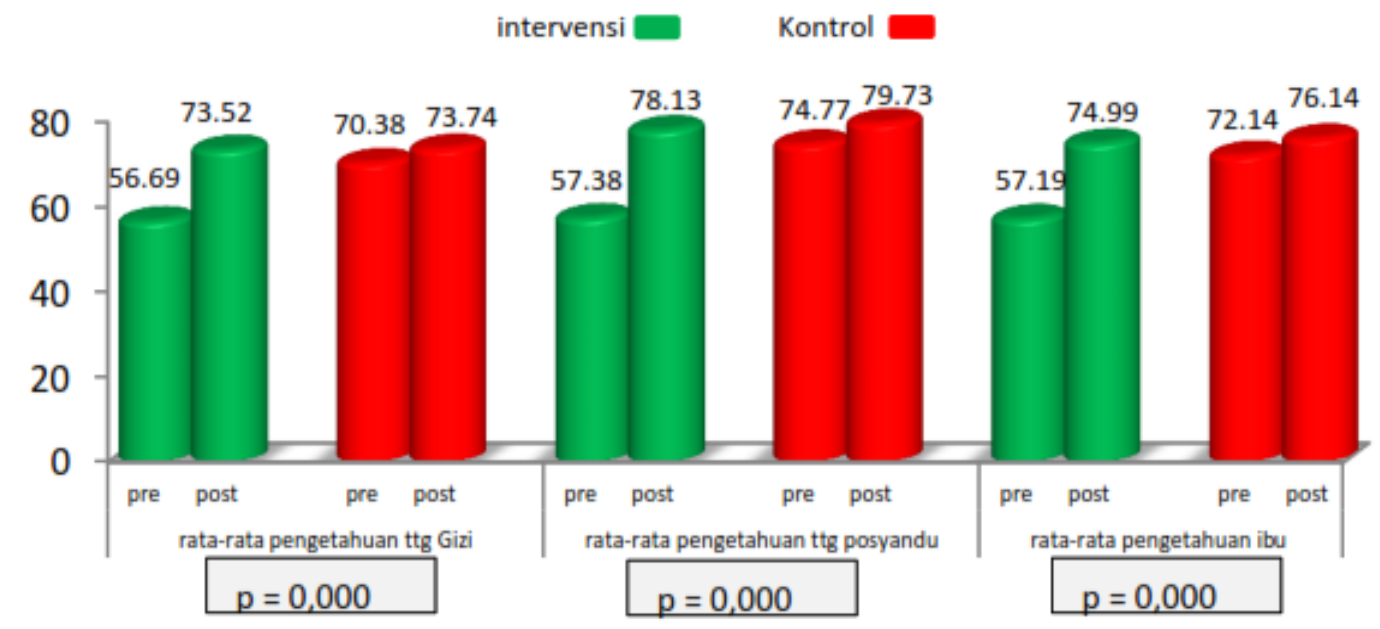

serta peningkatannya berbeda secara signifikan $(p=0,000)$. Artinya Ada perbedaan yang signifikan terhadap peningkatan asupan energi sebelum dan sesudah pelaksanaan kelas gizi masyarakat.

Tabel 2 menunjukkan bahwa ratarata berat badan anak sebelum pelaksanaan kelas gizi masyarakat pada kelompok intervensi yaitu 9,94 dengan berat badan minimum 6,2 dan maksimum 15,0 dan meningkat setelah kelas gizi masyarakat yaitu ratarata berat badan anak menjadi 10,15 dengan berat badan minimum 6,8 dan maksimum 15,0. Sedangkan pada kelompok kontrol sebelum pelaksanaan penyuluhan rata-rata berat badan anak yaitu 10,67 dengan berat badan minimum 6,1 dan maksimum 20,0 serta terdapat peningkatan setelah penyuluhan yaitu rata - rata berat badan anak menjadi 10,84 dengan berat badan minimum 6,7 dan maksimum 20,3. Rata - rata peningkatan berat badan anak balita pada kelompok intervensi yaitu $0,21 \mathrm{~kg}$ sedangkan pada kelompok kontrol yaitu $0,16 \mathrm{~kg}$.

Hasil uji statistik wilcoxon signed rank menunjukkan bahwa kegiatan kelas gizi masyarakat pada kelompok intervensi dan kegiatan penyuluhan pada kelompok kontrol, keduanya dapat meningkatkan berat badan anak balita serta peningkatannya berbeda secara signifikan $(\mathrm{p}=0,000)$. Artinya Ada perbedaan yang signifikan terhadap peningkatan berat badan anak sebelum dan sesudah pelaksanaan kelas gizi masyarakat pada kelompok intervensi dan kegiatan penyuluhan pada kelompok kontrol.

Pada tabel 3 menunjukkan bahwa tingkat partisipasi masyarakat yang membawa anaknya dan keberhasilan penimbangan balita di posyandu pada kelompok intervensi sebelum kegiatan kelas gizi masyarakat yaitu $\mathrm{D} / \mathrm{S}=50,86 \% \mathrm{~N} / \mathrm{D}=33,90$ meningkat setelah kegiatan kelas gizi masyarakat menjadi $\mathrm{D} / \mathrm{S}=78,5 \% \mathrm{~N} / \mathrm{D}=76,19$. Sedangkan pada kelompok kontrol sebelum penyuluhan yaitu $\mathrm{D} / \mathrm{S}=82,17 \% \mathrm{~N} / \mathrm{D}=79,25 \%$ meningkat setelah kegiatan kelas gizi masyarakat menjadi $\mathrm{D} / \mathrm{S}=85,84 \% \mathrm{~N} / \mathrm{D}=81,44 \%$. 
Tabel 3

Distribusi Cakupan Kinerja Posyandu Sebelum dan Seudah Mengikuti Kelas Gizi Masyarakat

\begin{tabular}{|c|c|c|c|c|c|c|c|c|c|c|}
\hline \multirow[t]{3}{*}{ Kelompok } & \multicolumn{10}{|c|}{ Kinerja Posyandu (D/S, N/D) } \\
\hline & \multicolumn{5}{|c|}{ Sebelum } & \multicolumn{5}{|c|}{ Setelah } \\
\hline & $\mathrm{S}$ & $\mathrm{D}$ & $\mathrm{N}$ & $\mathrm{D} / \mathrm{S}$ & $\mathrm{N} / \mathrm{D}$ & $\mathrm{S}$ & $\mathrm{D}$ & $\mathrm{N}$ & $\mathrm{D} / \mathrm{S}$ & $\mathrm{N} / \mathrm{D}$ \\
\hline Intervensi & 116 & 59 & 20 & 50,86 & 33,90 & 107 & 84 & 64 & 78,50 & 76,19 \\
\hline Ma'remme & 61 & 33 & 12 & 54,10 & 36,36 & 55 & 45 & 33 & 81,82 & 73,33 \\
\hline Bt.Tangga & 55 & 26 & 8 & 47,27 & 30,77 & 53 & 46 & 31 & 73,58 & 79,49 \\
\hline Kontrol & 129 & 106 & 84 & 82,17 & 79,25 & 113 & 97 & 79 & 85,84 & 81,44 \\
\hline Pataro & 68 & 56 & 45 & 82,35 & 80,36 & 61 & 53 & 43 & 86,89 & 81,13 \\
\hline Bt. Tappalang & 61 & 50 & 39 & 81,97 & 78,00 & 52 & 44 & 36 & 84,62 & 81,82 \\
\hline
\end{tabular}

\section{PEMBAHASAN}

Hasil penelitian menunjukkan peningkatan rata-rata skor pengetahuan ibu pada kelompok intervensi lebih tinggi yaitu 17,79 poin dari pada kelompok kontrol yang hanya 4,00 poin. Pengetahuan ibu pada kelompok kontrol yang hanya meningkat kecil, meski secara analisis statistik meningkat secara signifikan dan mengalami peningkatan pengetahuan sesudah penelitian. Hal ini disebabkan pengetahuan ibu balita pada kelompok kontrol sebelum intervensi telah mempunyai rerata skor pengetahuan yang agak tinggi. Peningkatan pengetahuan lebih tinggi kelompok intervensi dari kontrol disebabkan karena model intervensi yang diberikan berbeda, kelas gizi masyarakat (5 kali pertemuan) pada kelompok intervensi dan hanya penyuluhan (1 kali) pada kelompok kontrol dengan frekuensi yang berbeda.

Tingkat pendidikan ibu balita pada kelompok kontrol lebih tinggi dari kelompok intervensi, sehingga berbeda dalam hal pengetahuan gizi ibu balita sebelum intervensi. Setelah dilaksanakan kelas gizi pada kelompok intervensi, pengetahuan ibu balita hampir sama dengan kelompok kontrol. Perubahan dan peningkatan penge- tahuan pada kelompok perlakuan merupakan hasil dari kegiatan pendidikan kesehatan dalam jangka waktu pendek (Belski et al., 2018). Hasil temuan Lubis (2015) menunjukkan pengetahuan dan keterampilan kader dalam kegiatan penimbangan balita di posyandu meningkat setelah mengikuti training melalui metode dua arah, adanya dialog, proses simulasi dan praktik.

Program pendampingan dapat meningkatkan pengetahuan dan perubahan pola perilaku dalam pemenuhan gizi keluarga melalui kegiatan penyuluhan (Naulia et al., 2021; Siswanti et al., 2016). Tenaga gizi pendamping yang memberikan intervensi penyuluhan berpengaruh terhadap peningkatan pengetahuan ibu, baik untuk kesehatan bayinya maupun kesehatan ibu itu sendiri (Kustiani \& Misa, 2018; Simbolon et al., 2019). Penelitian ini sejalan dengan temuan Wirawan et al., (2014) bahwa kegiatan penyuluhan dengan menggunakan media AV maupun konvensional, keduanya dapat meningkatkan ratarata pengetahuan gizi ibu balita. Adanya kegiatan kelas gizi masyarakat yang dilakukan oleh peneliti memberikan gambaran bahwa peserta kelas gizi mengetahui, 


\section{Gambar 2}

Peningkatan Pola Asuh Ibu Balita Sebelum dan Seudah Mengikuti Kelas Gizi Masyarakat

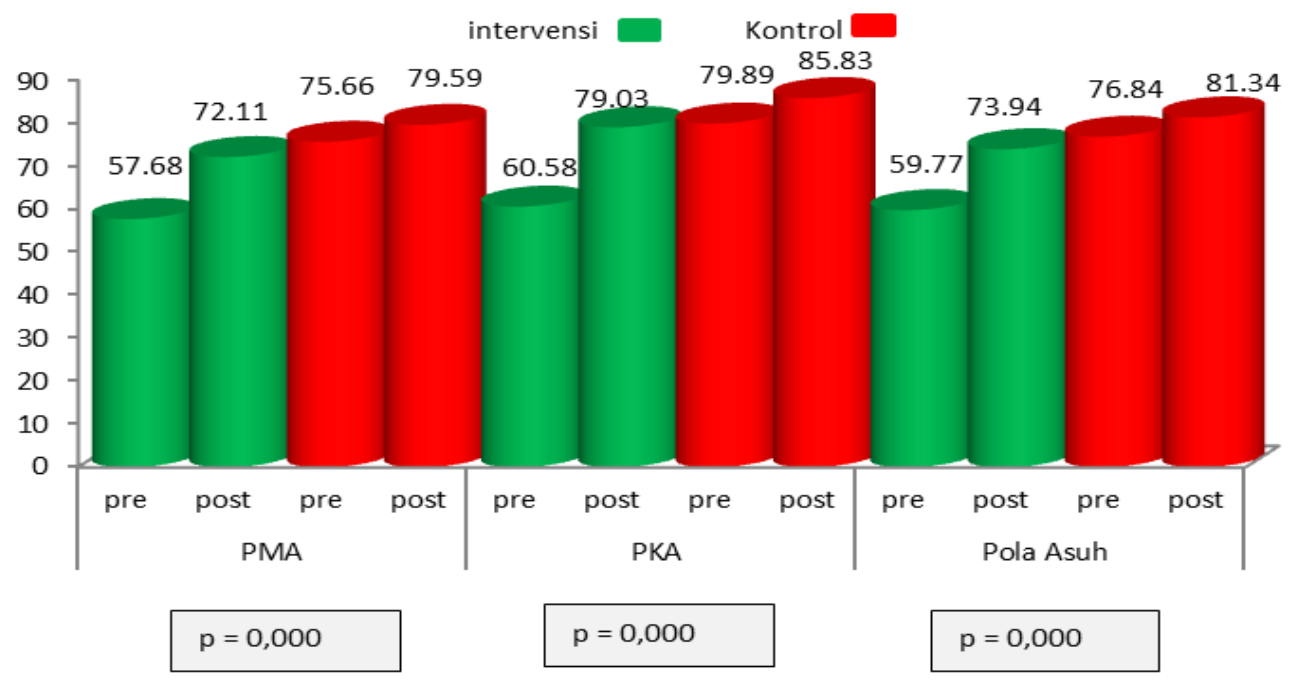

memahami serta mampu dan memiliki kemauan mempraktikkan tetang pengetahuan gizi dalam mengasuh anaknya dan kelas gizi masyarakat merupakan salah satu wadah dalam memantau status kesehatan anak karena tingginya pastisipasi ibu balita pada kegiatan di posyandu.

Pola pengasuhan ibu merupakan hal mutlak dilakukan dengan memberikan perawatan positif, ini akan berdampak pada proses pertumbuhan dan perkembangannya terutama pada usia emasnya. Faktor kesehatan ibu, pendidikan, pengetahuan dan keterampilan perawatan anak memiliki hubungan yang erat terhadap pola pengasuhan anak. Hasil uji statistik wilcoxon signed rank menunjukkan bahwa kelas gizi masyarakat dapat meningkatkan pola asuh ibu balita (PMA dan PKA) serta peningkatannya berbeda secara signifikan. Ini menunjukkan bahwa kelas gizi pada kelompok perlakuan dan kegiatan penyuluhan pada kelompok kontrol keduanya dapat meningkatkan pola pengasuhan ibu balita.

Ibu memiliki peranan yang utama dalam pengasuhan anak, pengetahuan ibu yang meningkat tentang gizi keluarga erat kaitannya dalam perbaikan praktik pengasuhan anak. Sehingga pesan gizi dan kesehatan yang berkaitan dengan pengasuhan anak dapat diimplementasikan oleh ibu sebagai pengasuh anak dalam kehidupannya. Ibu yang menerapkan pola asuh yang baik memberikan pengaruh terhadap tumbuh kembang anak pada setiap fase pertumbuhan (Aboud et al., 2013). Hal ini sejalan dengan penelitian Harahap et al. (2018) yang menyimpulkan bahwa asupan makanan yang adekuat dan pola asuh positif berhubungan dengan pertumbuhan dan perkembangan anak. Seorang anak yang memperoleh perawatan dan pengasuhan langsung dari ibu kandungnya dapat berinteraksi positif dibandingkan anak yang diasuh oleh keluarga atau orang lain. Pola pengasuhan anak akan berdampak dengan 
keadaan status gizi anak dan seorang ibu berusaha merangsang anaknya untuk konsumsi makananan yang adekuat sesuai kebutuhan gizinya (Gerards \& Kremers, 2015). Hasil penelitian Komariah (2019) tentang pola asuh dan status gizi anak di wilayah perkotaan Srijaya kota Palembang tahun 2017 menunjukkan ada hubungan antara pengetahuan ibu dengan tumbuh kembang anak serta terdapat hubungan pola asuh dengan tumbuh kembang anak dan perkembangan anak.

Terjadinya perubahan status gizi pada anak ibu yang mengikuti kegiatan kelas gizi dipengaruhi oleh keadaan status gizi anak sebelum adanya perlakuan yang diberikan. Setelah dilakukan intervensi diperoleh adanya perubahan keadaan status gizi baik yang lebih banyak dari anak balita yang mengalami gizi kurang dibandingkan kelompok kontrol. Hal ini menggambarkan untuk memulihkan keadaan gizi kurang menjadi baik dapat teratasi dalam jangka waktu satu bulan. Hasil uji statistik menunjukkan bahwa kelas gizi masyarakat dapat meningkatkan asupan energi anak balita serta peningkatannya berbeda secara signifikan. Kegiatan kelas gizi masyarakat yang dilasanakan pada penelitian ini memberikan pengaruh terhadap meningkatnya pengetahuan, pola pengasuhan anak dan praktik pemberian makanan anak. Anak akan memperoleh makanan yang bergizi sesuai dengan kebutuhannya dipengaruhi oleh praktik pemberian makan dar ibu atau pengasuhnya. Meskipun status gizi balita pada kelompok intervensi meningkat setelah kegiatan kelas gizi masyarakat, namun masih ada pula anak balita yang status gizi tidak berubah dari yang semestinya. Hal tersebut disebabkan karena adanya balita yang terinfeksi penyakit dan asupan zat gizi tidak adekuat dan memadai sesuai dengan AKG dan kebutuhan. Penyakit infeksi yang diderita oleh seorang anak mempengaruhi selera makan anak sehingga terjadi penurunan asupan energi sehingga memudahkan seorang anak mengalami status gizi kurang atau gizi buruk.

Rendahnya partisipasi masyarakat pada kelompok intervensi sebelum pelaksanaan kelas gizi dipengaruhi oleh tingkat pendidikan dan pengetahuan ibu tentang manfaat posyandu. Pada penelitian ini ditemukan bahwa tingkat pendidikan pada kelompok intervensi sebagian besar hanya tamat SD dan rata-rata pengetahuan ibu tentang gizi balita dan posyandu hanya $57,19 \%$ dan pola pengasuhan anak 59,77\%. Sedangkan pada kelompok kontrol umumnya tingkat pengetahuan ibu tamat SMA dan rata-rata pengetahuan ibu tentang gizi balita dan posyandu hanya $72,14 \%$ dan pola pengasuhan anak $76,84 \%$.

Meningkatnya partisipasi masyarakat yang membawa anaknya ke posyandu (D/ S) dan meningkatnya jumlah anak balita yang naik berat badannya dari penimbangan bulan sebelumnya (N/D) menunjukkan bahwa kegiatan kelas gizi masyarakat memberikan dampak positif terhadap meningkatnya pengetahuan dan pola pengasuhan anak, khususnya tentang perubahan perilaku ibu dalam membawa anaknya menimbang di posyandu yang ingin mengetahui keadaan status gizi anak. Terjadinya perbaikan tentang cara dan praktik pemberian makan berefek pada pemenuhan 
gizi anak baik dari aspek kualitas dan kuantitas yang pada akhirnya terjadi pertambahan berat badan anak sehingga berpengaruh pada capaian N/D pada posyandu tersebut. Hal ini menunjukkan bahwa penyuluhan gizi pada kegiatan pendampingan gizi merupakan salah satu model pendekatan yang dilakukan untuk mengubah perilaku yang baik dalam pengasuhan anak melalui peningkatan pengetahuan gizi pada ibu. Hal ini sejalan dengan model intervensi yang terapkan melalui kelas gizi masyarakat dapat meningkatkan pengetahuan dan kesadaran ibu pada kegiatan di posyandu. Hasil penelitian menunjukkan setelah kegiatan kelas gizi masyarakat tingkat partisipasi masyarakat menjadi $\mathrm{D} / \mathrm{S}=$ $78,5 \%$ dan $\mathrm{N} / \mathrm{D}=76,19 \%$.

Daya ingat seseorang terhadap informasi yang diterima berkurang seiring berjalannya waktu, semakin lama semakin berkurang yang pada akhirnya orang tersebut mengalami kelupaan (Inda et al., 2011). Hal demikian dapat terjadi pada ibu balita yang telah memperoleh informasi tentang pengetahuan gizi dan pola pengasuhan anak jika tidak dipraktikan dan terjadinya penurunan intensitas informasi kesehatan dari petugas kesehatan berdampak pada respon ibu terhadap materi yang pernah diberikan pada saat kelas gizi masyarakat. Dari fenomena tersebut diharapkan kepada petugas puskesmas atau kader posyandu melalui pokja kesehatan desa untuk mendorong agar kiranya kegiatan peningkatan pengetahuan dan kemampuan pola asuh ibu melalui kelas gizi masyarakat dapat dilaksanakan secara berkala dan rutin. Pendidikan gizi yang diperoleh melalui kelas gizi masyarakat dan adanya dukurngan dari stakeholder terkait dalam pelaksanaannya memberikan dampak terhadap perbaikan gizi masyarakat terkhusus pada status gizi dan kesehatan balita.

\section{KESIMPULAN}

Kelas gizi masyarakat di posyandu dapat dijadikan sebagai salah satu model dalam memperbaiki tingkat partisipasi masyarakat di posyandu karena terjadi perubahan baik pengetahuan, pola asuh ibu pada anak, jumlah kunjungan di posyandu dan jumlah balita yang naik berat badannya dari penimbangan bulan sebelumnya meningkat secara signifikan.

Penelitian ini masih perlu dilanjutkan dengan memantau tingkat partisipasi ibu balita di posyandu dan efektivitas pelaksanaan kelas gizi masyarakat. Hasil penelitian ini direkomendasikan bagi pihak Dinas Kesehatan Kabupaten Bulukumba sebagai kegiatan yang dapat direplikasi untuk meningkatkan kinerja di posyandu dan status kesehatan anak.

\section{DAFTAR PUSTAKA}

Aboud, F. E., Singla, D. R., Nahil, M. I., \& Borisova, I. (2013). Effectiveness of a parenting program in Bangladesh to address early childhood health, growth and development. Social Science \& Medicine, 97, 250258. https://doi.org/10.1186/s12887-015-0514 $-5$

Abuya, B. A., Ciera, J., \& Kimani-Murage, E. (2012). Effect of mother's education on child's nutritional status in the slums of Nairobi. BMC pediatrics, 12(1), 1-10. https:// doi.org/10.1186/1471-2431-12-80

Adistie, F., Lumbantobing, V. B. M., \& Maryam, N. N. A. (2018). Pemberdayaan Kader Kesehatan Dalam Deteksi Dini Stunting dan Stimulasi Tumbuh Kembang pada Balita. Media Karya 
Kesehatan, 1(2). https://doi.org/10.24198/ mkk.v1i2.18863

Aminuddin, A., Zulkifli, A., \& Djafar, N. (2011). Peningkatan Peran Posyandu Partisipatif melalui Pendampingan dan Pelatihan Upaya Pemantauan Pertumbuhan dan Masalah Gizi Balita di Bone, Sulawesi Selatan. Kesmas: Jurnal Kesehatan Masyarakat Nasional (National Public Health Journal), 5(5), 201205.

http://dx.doi.org/10.21109/kesmas.v5i5.127

Belski, R., Donaldson, A., Staley, K., Skiadopoulos, A., Randle, E., O’Halloran, P., \& Nicholson, M. (2018). Brief education intervention increases nutrition knowledge and confidence of coaches of junior Australian football teams. International journal of sport nutrition and exercise metabolism, 28(3), 259265. https://doi.org/10.1123/ijsnem.20170170

Budiono, I. (2013). Pengembangan Model Indeks Pembangunan Gizi. KEMAS: Jurnal Kesehatan Masyarakat, 8(2). https://doi.org/10.15294/kemas.v8i2.2641

Chan, C. Q. H., Lee, K. H., \& Low, L. L. (2018). A systematic review of health status, health seeking behaviour and healthcare utilisation of low socioeconomic status populations in urban Singapore. International journal for equity in health, 17(1), 1-21. https://doi.org/10.1186/s12939-018-0751-y

Criss, S., Baidal, J. A. W., Goldman, R. E., Perkins, M., Cunningham, C., \& Taveras, E. M. (2015). The role of health information sources in decision-making among Hispanic mothers during their children's first 1000 days of life. Maternal and child health journal, 19(11), 2536-2543. https://doi.org/10.1007/s10995-015-1774-2

Delaney, L. J. (2018). Patient-centred care as an approach to improving health care in Australia. Collegian, 25(1), 119-123. https://doi.org/10.1016/j.colegn.2017.02.005

Destiadi, A., Nindya, T. S., \& Sumarmi, S. (2015). Frekuensi Kunjungan Posyandu dan Riwayat Kenaikan Berat Badan sebagai Faktor Risiko Kejadian Stunting pada Anak Usia 3-5 Tahun. Media Gizi Indonesia, 10(1), 71-75. http://dx.doi.org/10.20473/mgi.v10i1.71-75

Di Cesare, M., Bhatti, Z., Soofi, S. B., Fortunato, L., Ezzati, M., \& Bhutta, Z. A. (2015). Geo- graphical and socioeconomic inequalities in women and children's nutritional status in Pakistan in 2011: an analysis of data from a nationally representative survey. The Lancet Global Health, 3(4), e229-e239. https://doi.org/10.1016/S2214109X(15)70001-X

Dinas Kesehatan Kabupaten Bulukumba (2015). Profil Kesehatan Kabupaten Bulukumba Tahun 2014. In Sistem Informasi Kesehatan. https://pusdatin.kemkes.go.id/resources/dow nload/profil/PROFIL_KAB_KOTA_2014/73 02_Sulsel_Kab_Bulukumba_2014.pdf

Gerards, S. M. P. L., \& Kremers, S. P. J. (2015). The role of food parenting skills and the home food environment in children's weight gain and obesity. Current obesity reports, 4(1), 30-36. https://doi.org/10.1007/s13679-015-0139-x

Hafifah, N., \& Abidin, Z. (2020). Peran Posyandu dalam Meningkatkan Kualitas Kesehatan Ibu dan Anak di Desa Sukawening, Kabupaten Bogor. Jurnal Pusat Inovasi Masyarakat (PIM), 2(5), 893-900. https://journal.ipb.ac.id/index.php/pim/article /view/31742

Harahap, H., Budiman, B., \& Widodo, Y. (2018). Gangguan pertumbuhan dan perkembangan pada anak usia 0, 5-1, 9 tahun terkait dengan asupan makanan dan pengasuhan yang kurang. Gizi Indonesia, 41(1), 49-58. http://dx.doi.org/10.36457/gizindo.v41i1.247

Inda, M. C., Muravieva, E. V., \& Alberini, C. M. (2011). Memory retrieval and the passage of time: from reconsolidation and strengthening to extinction. Journal of Neuroscience, 31(5), 1635-1643. https://doi.org/10.1523/JNEUROSCI.473610.2011

Indrawati, L., \& Tjandrarini, D. H. (2018). Peran indikator pelayanan kesehatan untuk meningkatkan nilai sub indeks kesehatan reproduksi dalam Indeks Pembangunan Kesehatan Masyarakat (IPKM). Media Penelitian dan Pengembangan Kesehatan, 28(2), 95-102. https://doi.org/10.22435/mpk.v28i2.180

Indriati, R., \& Lidyawati, C. (2017). Hubungan tingkat partisipasi ibu mengikuti posyandu dengan status gizi balita di Desa Mulur rt 03/VI Bendosari Sukoharjo. KOSALA: Jurnal Ilmu Kesehatan, 5(1). https://doi.org/10.37831/jik.v5i1.112 
Islam, R., Adams, A. M., Hasan, S. M., Ahmed, R., Bhattacharyya, D. S., \& Shafique, S. (2020). Protocol: Making information and communications technologies (ICTs) work for health: protocol for a mixed-methods study exploring processes for institutionalising geo-referenced health information systems to strengthen maternal neonatal and child health $(\mathrm{MNCH})$ service planning, referral and oversight in urban Bangladesh. BMJ Open, 10(12). https://dx.doi.org/10.1136\%2Fbmjopen-2019032820

Kartika, K., Mufida, N., Karmila, K., \& Marlina, M. (2018). Faktor Yang Mempengaruhi Peran Kader Dalam Upaya Perbaikan Gizi Pada Balita di Wilayah Kerja Puskesmas Mila. Jurnal Kesehatan Global, 1(2), 45-52. https://doi.org/10.33085/jkg.v1i2.3980

Komariah, N. (2019). Knowledge and Parenting Patterns with Toddler's Growth and Development. International Journal of Public Health Science, $\quad 8(2), \quad 179-184$. https://dx.doi.org/10.11591/ijphs.v8i2.17808

Kosasih, C. E., Purba, C. I. H., \& Sriati, A. (2018). Upaya Peningkatan Gizi Balita Melalui Pelatihan Kader Kesehatan di Desa Cilumba dan Gunungsari Kabupaten Tasikmalaya. Media Karya Kesehatan, 1(1). https://doi.org/10.24198/mkk.v1i1.16945

Kustiani, A., \& Misa, A. P. (2018). Perubahan Pengetahuan, Sikap, dan Perilaku Ibu dalam Pemberian MP-ASI Anak Usia 6-24 Bulan pada Intervensi Penyuluhan Gizi di Lubuk Buaya Kota Padang. Jurnal Kesehatan Perintis (Perintis's Health Journal), 5(1), 51-57. https://doi.org/10.33653/jkp.v5i1.94

Lubis, Z. (2015). Pengetahuan dan tindakan kader posyandu dalam pemantauan pertumbuhan anak balita. KEMAS: Jurnal Kesehatan Masyarakat, $\quad 11(1), \quad 65-73$. https://doi.org/10.15294/kemas.v11i1.3473

Megawati, G., \& Wiramihardja, S. (2019). Peningkatan Kapasitas Kader Posyandu Dalam Mendeteksi Dan Mencegah Stunting. Dharmakarya, 8(3), 154-159. https://doi.org/10.24198/dharmakarya.v8i3.20 726

Naulia, R. P., Hendrawati, H., \& Saudi, L. (2021). Pengaruh Edukasi Gizi Terhadap Pengetahuan dan Sikap Ibu dalam Pemenuhan Nutrisi Balita Stunting. Jurnal Ilmu Kesehatan Masyarakat, 10(02), 95-101. https://doi.org/10.33221/jikm.v10i02.903

Pratley, P. (2016). Associations between quantitative measures of women's empowerment and access to care and health status for mothers and their children: a systematic review of evidence from the developing world. Social Science \& Medicine, 169, 119-131. https://doi.org/10.1016/j.socscimed.2016.08.0 01

Ranehov, L., \& Håkansson, C. (2019). Mothers' experiences of their work as healthcare assistants for their chronic disabled child. Scandinavian journal of occupational therapy, 26(2), 121-134. https://doi.org/10.1080/11038128.2018.14834 27

Saepuddin, E., Rizal, E., \& Rusmana, A. (2017). Posyandu Roles as Mothers and Child Health Information Center. Record and Library Journal, 3(2), 201-208. http://dx.doi.org/10.20473/rlj.V3I2.2017.201-208

Simbolon, D., Rahmadi, A., \& Jumiyati, J. (2019). Pengaruh Pendampingan Gizi terhadap Perubahan Perilaku Pemenuhan Gizi Ibu Hamil Kurang Energi Kronik (KEK). Jurnal Kesehatan, 10(2), 269-275. http://dx.doi.org/10.26630/jk.v10i2.1366

Siswanti, A. D., Muadi, S., \& Chawa, A. F. (2016). Peran pendampingan dalam program pemberdayaan masyarakat (studi pada program pendampingan keluarga balita gizi buruk di kecamatan semampir kota surabaya). Wacana Journal of Social and Humanity Studies, 19(3). https://wacana.ub.ac.id/index.php/wacana/arti cle/view/417

Tjandra, D. H., Mubasyiroh, R., \& Dharmayanti, I. (2018). Pencapaian Indonesia Sehat Melalui Pendekatan Indeks Pembangunan Kesehatan Masyarakat Dan Indeks Keluarga Sehat. Buletin Penelitian Sistem Kesehatan, 21(2), 90-96. https://doi.org/10.22435/hsr.v21 i2.314

Wirawan, S., Abdi, L. K., \& Sulendri, N. K. S. (2014). Penyuluhan dengan media audio visual dan konvensional terhadap pengetahuan ibu anak balita. KEMAS: Jurnal Kesehatan Masyarakat, $\quad$ 10(1), 80-87. https://doi.org/10.15294/kemas.v10i1.3073

Yogiswara, B. A., \& Margawati, A. (2011). Hubungan antara tingkat partisipasi 
ibu Di posyandu dengan status gizi balita (Doctoral dissertation, Faculty of Medicine). http://eprints.undip.ac.id/32880/ 